\title{
Variabilidade temporal no transporte de sedimentos no rio Ivaí - Paraná (1977-2007)
}

\author{
Isabel Terezinha Leli ${ }^{1}$, Jose Cândido Stevaux ${ }^{2}$, Maria Tereza da Nóbrega ${ }^{3}$ \& \\ Edvard Elias de Souza Filho ${ }^{2}$
}

\begin{abstract}
Resumo Este trabalho avalia o comportamento da carga sedimentar suspensa do rio Ivaí num período de 30 anos aferidos por sua estação mais jusante de Novo Porto Taquara. Os parâmetros utilizados neste estudo foram as descargas anuais de sedimento suspenso e de água obtidas a partir de dados da SUDERSA. A relação entre a concentração de sedimento suspenso e a descarga de água não apresentou uma correlação muito boa $\left(\mathrm{R}^{2}=0,56\right)$, sendo bastante evidente o efeito de histerese. A justificativa para esse comportamento é dada pelo regime hidrológico heterogêneo e pela ocupação da bacia. Não foram observadas alterações significativas nas vazões anuais, que permaneceram as mesmas durante o período estudado. Já a descarga de sedimento suspenso apresentou um pequeno declínio gradual mostrando que no final do período (2007), o rio transporta 0,65 Mton menos do que no começo (1977). Esta redução de sedimento suspenso transportado é provavelmente devido a alterações no manejo do solo para o cultivo agrícola.
\end{abstract}

Palavras-chave: sedimento suspenso, regime fluvial, manejo de bacia, vazão fluvial, descarga fluvial.

\begin{abstract}
Temporal variability in transportation of sediment in the river Ivaí-Paraná (1977-2007). This paper evaluates the behavior of suspended sediment load of the river Ivaí over a period of 32 years measured by the station further downstream the river (Novo Porto Taquara). The most suitable parameters for this assessment were the annual discharge of suspended sediment and water obtained from SUDERSA. The relationship between the concentration of suspended sediment and discharge of water had not a very good correlation $\left(\mathrm{R}^{2}=0,56\right)$ and hysteresis effect is quite clear. The justification for this behavior is given by the heterogeneity of the hydrological regime and basin occupation. There were no significant changes in annual flows which have remained the same during the study period. Already the discharge of suspended sediment showed a small gradual decline in which the end of the period (2007), the river carries less than 0.65 Mton at the beginning (1977). This reduction in suspended sediment transported is probably due to changes in soil management for agriculture.
\end{abstract}

Keywords: suspended sediment, river regime, basin management, river flow, river discharge.

INTRODUÇÃO Os sistemas fluviais se comportam de maneira exclusiva e marcante na relação entre o fluxo e transporte de sedimentos, portanto, segundo o autor Restrepo (2005), é correto afirmar que os rios apresentam variabilidade temporal e espacial no transporte de sedimentos em suspensão, e dependendo do sistema, essa variabilidade pode ser maior ou menor. $\mathrm{O}$ sistema se torna mais eficiente no que se refere ao transporte de sedimentos e carga dissolvida à medida que aumenta a vazão.

A magnitude da vazão e, por conseguinte, a capacidade de transporte, podem ser modificadas por fatores de diferentes intervenções, como por exemplo: 1) variação climática sazonal, 2) variação no suprimento de sedimento, 3) mudanças morfológicas nas seções dos rios, 4) variação nos processos que controlam a capacidade de erodir e transportar (Morehead et al. 2003).

As variações na concentração de sedimento são analisadas sob diferentes escalas temporais: horárias, diárias, sendo, entretanto, mais frequente a utilização da descarga anual quando a intenção é avaliar alterações no regime das descargas de água e sedimento, bem como dos fluxos que alteram a geomorfologia dos canais fluviais (Pitlik 1993). Por outro lado pode-se afirmar que, embora cada bacia hidrográfica tenha sua especificidade no processo de coleta e descarga de sedimentos, a variação de carga sedimentar está estreitamente relacionada com as diferenças do regime climático e a geomorfologia da bacia (Parker 1976, Morehead et al. 2003).

A variação temporal no transporte de sedimento nos canais fluviais é estudada com diversos objetivos, mas com o intuito comum de gerenciar o sistema de coleta, transporte e deposição do sedimento. Este tipo de estudo permite avaliar a interferência das atividades humanas, através da variação na quantidade de sedimento que o canal aporta associada às mudanças do uso do solo, como também, dá uma ideia de como diferentes estruturas de engenharia (balsas, pontes, desvios de

1 - Pós-Graduação em Geologia e Meio Ambiente, Instituto de Geociências e Ciências Exatas, Universidade Estadual Paulista, Rio Claro (SP), Brasil. E-mail: isa-leli@hotmail.com

2 - Grupo de Estudos Multidisciplinares do Ambiente - GEMA, Universidade Estadual de Maringá, Maringá (PR), Brasil. E-mail: josecstevaux@gmail.com, eesfilho@uem.br

3 - Departamento de Geografia, Universidade Estadual de Maringá, Maringá (PR), Brasil. E-mail: mtnobrega@uol.com.br 
canais, represamentos, canalização etc.) afetam o fluxo da água e sedimentos ao longo dos rios.

O estudo da variação temporal e das tendências no transporte de sedimento possibilita a elaboração de modelos numéricos necessários e capazes de predizer a descarga de sedimento para bacias que estão sob as mais diferentes situações de mudanças climáticas, bem como, as variações ambientais produzidas pelas diferenças de uso e ocupação do solo. Dentro desta perspectiva, o presente trabalho pretende analisar a relação da carga de sedimento suspenso e vazão do rio Ivaí para os anos de 1977 a 2007. Este período de análise resulta da série histórica existente e obtida pela Superintendência de Desenvolvimento de Recursos Hídricos e Saneamento Ambiental - SUDERHSA.

LOCALIZAÇÃO E CARACTERÍSTICAS DA BACIA DO RIO IVAÍ A bacia hidrográfica do rio
Ivaí está localizada na região sul do Brasil (2256'17'”$-25^{\circ} 35^{\prime} 27^{\prime \prime} \mathrm{S}$ e $50^{\circ} 44^{\prime} 17^{\prime}$ '-53'41'43'W) e constitui a segunda maior bacia do estado do Paraná com uma área de $36.587 \mathrm{~km}^{2}$ e vazão média, na estação Novo Porto Taquara, de $689,41 \mathrm{~m}^{3} / \mathrm{s}$. O rio Ivaí nasce no sudeste do estado, na Serra da Boa Esperança (Segundo Planalto paranaense), a $800 \mathrm{~m}$ de altitude e percorre uma distância de $720 \mathrm{~km}$ até desaguar na margem esquerda do rio Paraná, a $240 \mathrm{~m}$ de altitude (Fig. 1).

O rio Ivaí apresenta ciclo hidrológico com picos de cheias bem diferenciados da linha de vazão média. (Fig. 2). Isso ocorre pelo formato alongado da bacia, que proporciona rápido escoamento das vertentes $\mathrm{e}$, consequentemente, rápida resposta de subida e descida dos níveis de água no canal (Fig. 3).

Considerando as características físicas do rio Ivaí, Destefani (2005) sugeriu uma subdivisão em três segmentos (Fig. 1):

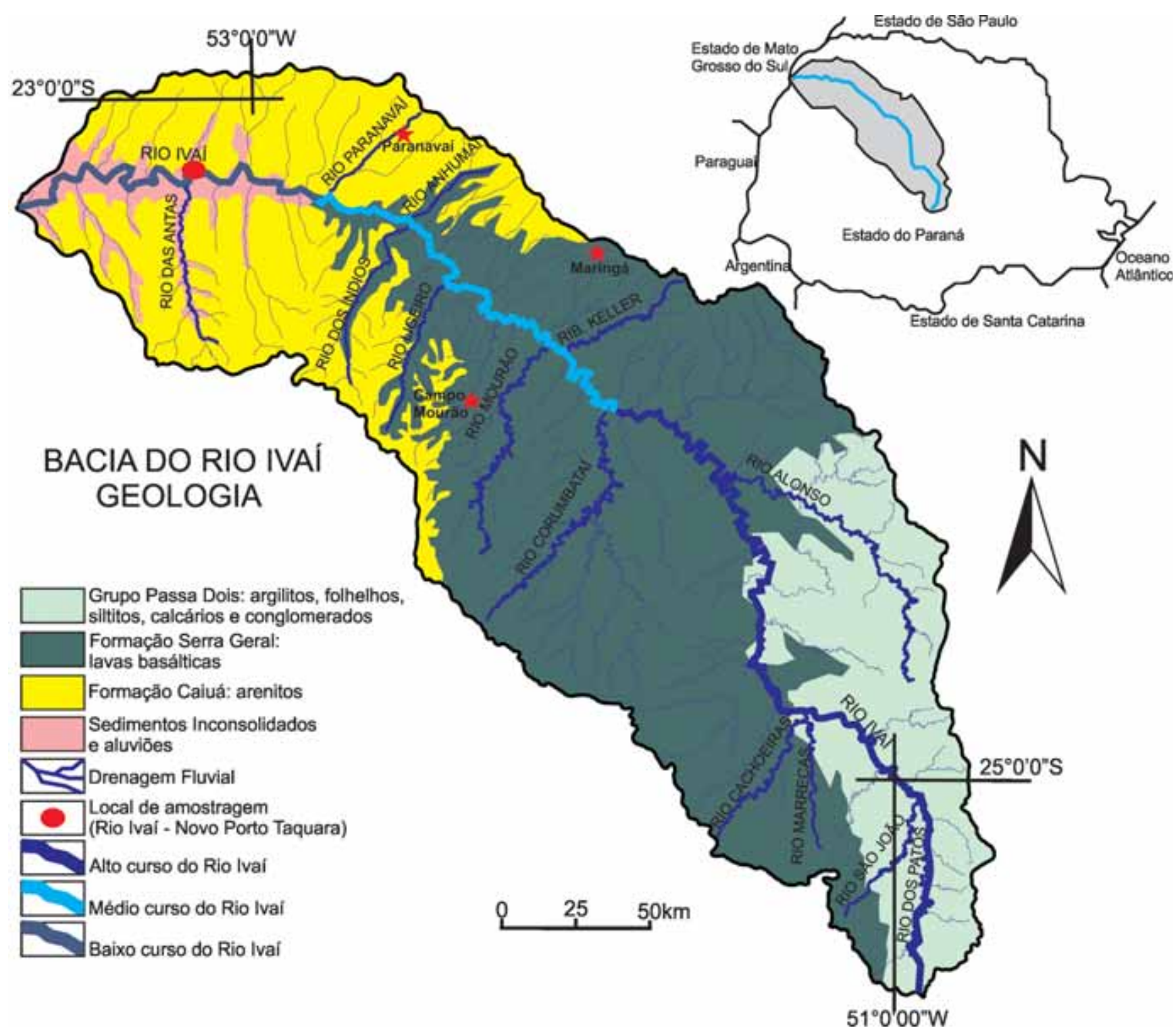

Figura 1 - Mapa geológico simplificado da bacia do rio Ivaí. Obs.: alto, médio e baixo curso do rio Ivaí, modelo proposto por Destefani (2005). 


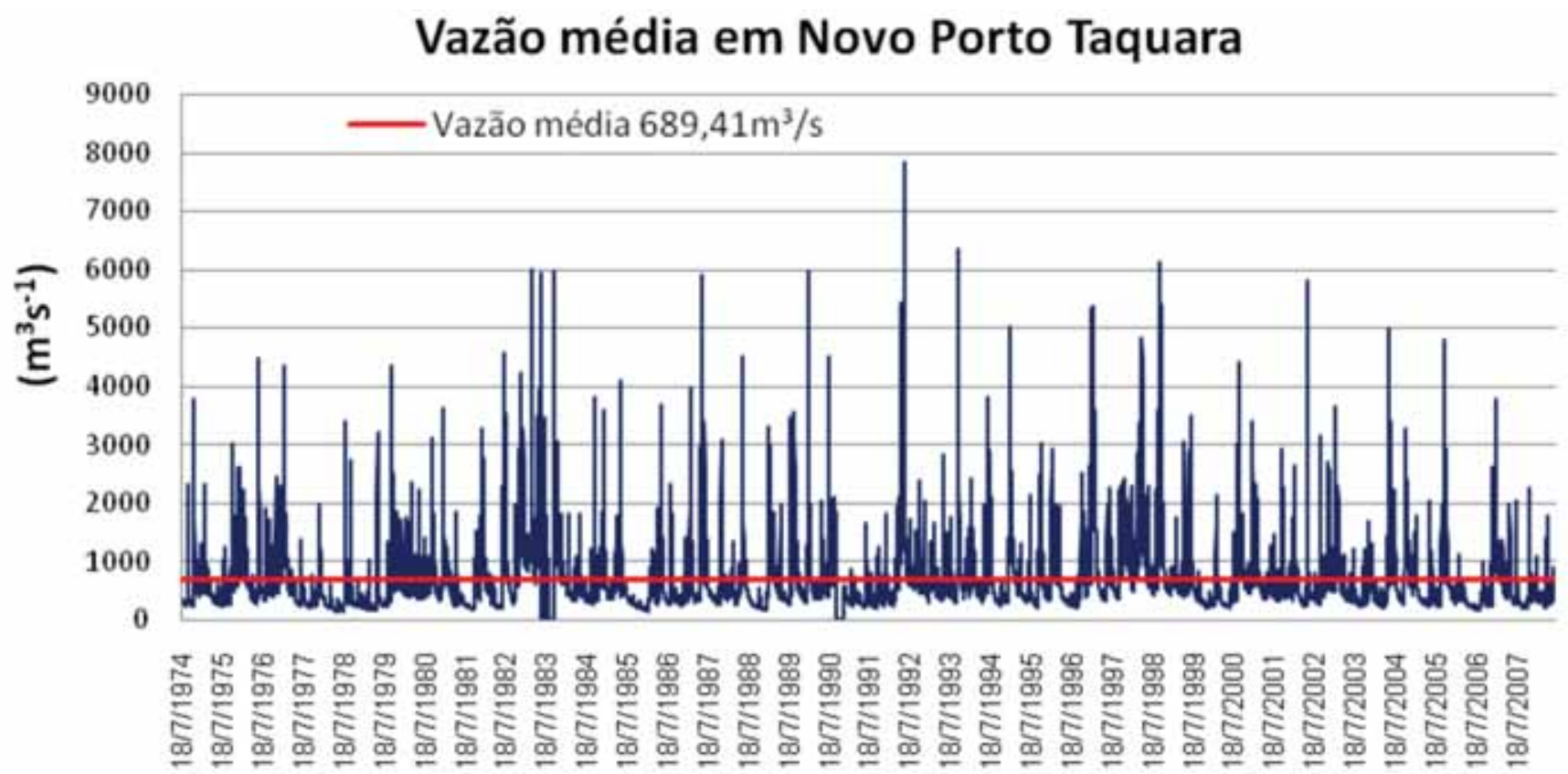

Figura 2 - Hidrograma do rio Ivaí da estação de Novo Porto Taquara no período de 1974-2008.

1) Segmento Superior: este trecho da bacia, entre as cotas 1.200 a $508 \mathrm{~m}$, é marcado por desníveis mais acentuados sendo comum a presença de cachoeiras e corredeiras no rio Ivaí e em seus tributários. O substrato é formado de rochas sedimentares paleozoicas da Bacia do Paraná (argilitos, folhelhos, siltitos, calcários entre outras), que mergulham suavemente para oeste. Sobre este substrato geológico o relevo é movimentado e dissecado, formado por topos planos e vertentes íngremes. Deste modo, o rio corta um relevo de "serra", em degraus, constituído por morros testemunhos e cadeias de mesetas (Maack 1981). A presença de intrusões de diabásio (sills e diques) potencializa a ocorrência de knickpoints (saltos e corredeiras). A cobertura pedológica é predominantemente formada de solos rasos do tipo Neossolos Litólicos e Cambissolos.

2) Segmento Médio: neste segmento, entre as cotas 508 a $280 \mathrm{~m}$, o rio Ivaí corta o basalto da Formação Serra Geral (K) da Bacia do Paraná. A ocorrência de derrames, característica dessas rochas, facilita a formação de quebras no perfil longitudinal do rio em formas de corredeiras e saltos. Se comparado ao Segmento Superior, neste setor o rio atravessa um relevo de patamares e mesetas menos enérgico, com morros mais arredondados conforme avança para jusante. Associados a essas características de relevo ocorrem os Nitossolos Vermelhos e Latossolos Vermelhos férricos mais espessos.

3) Segmento Inferior: neste trecho, entre as cotas 280 a 240 m, o rio Ivaí passa a escoar sobre os arenitos da Formação Caiuá e dos sedimentos aluviais da planície. O gradiente do canal se reduz acompanhando a topografia formada por chapadas e colinas bastante suaves. É rara a ocorrência de corredeiras neste trecho e quando ocorrem estão ligadas ao afloramento do "arenito Caiuá" no fundo do canal (Santos et al. 2008). Esse setor da bacia se encontra recoberto por Latossolos e Argissolos derivados dos arenitos da Formação Caiuá e por solos aluviais e hidromórficos (Neossolos Flúvicos e Gleissolos) na região restrita à planície aluvial do rio.

A bacia apresenta forma alongada (índice de compacidade $=1,64)$ orientada aproximadamente na direção NW-SE, o que a situa numa área de transição de clima com características tropicais para subtropicais. Em decorrência disso e do efeito orográfico, a bacia apresenta distribuição pluvial desigual, com maior intensidade na porção superior e média (1.800 e 1.600 $\mathrm{mm}$, respectivamente) diminuindo para o setor baixo (1.300 mm) (Andrade 2003, Baldo 2006).

Os setores, alto e médio, da bacia apresentam clima do tipo subtropical com distribuição temporal homogênea das chuvas que pode ocorrer em qualquer época do ano, enquanto, na parte inferior, o clima tende ao tropical com concentrações de chuva no verão e diminuição no inverno.

A vegetação da bacia se diferencia, principalmente, devido às condições do relevo e clima. Na porção média e alta, a ocorrência de geadas é mais frequente por causa do relevo acidentado, e potencializado pelo clima subtropical. Em virtude deste fato, a agricultura é bastante modesta podendo ocorrer ainda setores ocupados por vegetação primária do tipo subtropical. A parte média-baixa tem características de relevo e clima mais apropriados para mecanização agrícola. Estas características promoveram o intenso desmatamento para, primeiramente, a implantação da cultura cafeeira que sobreviveu até a década de 70, quando as plantações cafeeiras sofreram um agravo de geada intensa, gerando grande prejuízo e fim desse sistema agrícola. O declínio 


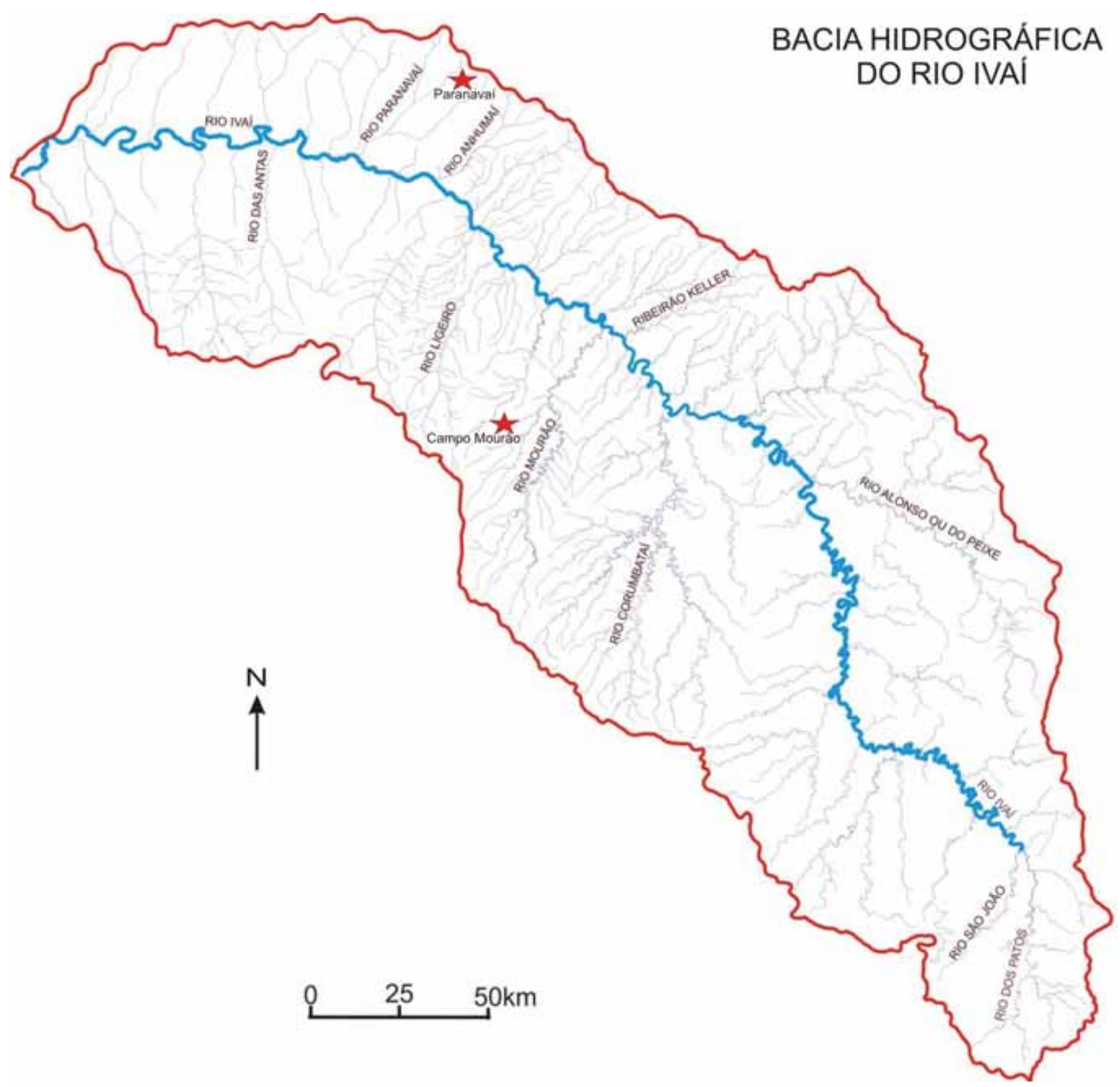

Figura 3 - Bacia hidrográfica do rio Ivaí.

da cultura do café promoveu e solidificou o processo de substituição de culturas, cedendo espaço para a cultura associada da soja e do trigo e para as pastagens. A introdução gradativa nos últimos 30 anos e a grande ascensão entre os anos de 1970 a 1985, dessas culturas comerciais, foi acompanhada e promovida pelo processo de modernização da agricultura paranaense (Moro 1991).

MÉTODOS Foram feitos levantamentos bibliográficos de trabalhos já realizados na região, em especial os relatórios da ITAIPU (1990) e Wilson-Jr et al. Os dados de vazão, pluviosidade e sedimento suspenso que resultaram na série histórica (1977-2008) foram fornecidos pela Superintendência de Desenvolvimento de Recursos Hídricos e Saneamento Ambiental - SUDERHSA. Como apoio aos dados da série histórica, e para que o trabalho pudesse ter envolvimento direto com o conhecimento dessas variáveis analisadas (vazão, pluviosidade e, principalmente, sedimento suspenso), foram realizadas coletas e análises mensais de água do rio Ivaí na estação Novo Porto Taquara, indicada na figura 1 durante 12 meses. O processo de análise em laboratório para quantificar o sedimento transportado foi executado conforme a metodologia de filtração por Millipore (Carvalho 1994). As análises foram executadas no Laboratório de Sedimentologia do GEMA/DGE/UEM.

RESULTADOS E DISCUSSÃO A estação Novo Porto Taquara localiza-se no município de Douradina - PR ( $23^{\circ} 12^{\prime} 00^{\prime \prime}$ e $\left.53^{\circ} 19^{\prime} 00^{\prime \prime}\right)$, a $240 \mathrm{~m}$ de altitude e aproximadamente $80 \mathrm{~km}$ da foz do rio e corresponde a uma área de drenagem de $34.432 \mathrm{~km}^{2}, 94 \%$ da bacia. 
Conforme o trabalho de Destefani (2005), o fluviograma da série histórica mostra um regime hidrológico com uma variabilidade significativa das vazões com rápidas mudanças de magnitude (Fig. 2). O coeficiente de variação, baseado na vazão média diária para o rio Ivaí, é diferente dependendo dos locais de amostragem ao longo do seu percurso. Esse parâmetro é expresso pelo inverso da vazão média da série histórica de vazões diárias $(\mathrm{Qm})$ pelo seu desvio padrão $(\sigma)$ :

$$
\mathrm{Cv}=\sigma / \mathrm{Qm}
$$

Destefani (2005) calculou o coeficiente de dispersão para alguns locais do rio Ivaí e indicou que a primeira estação a montante da bacia (rio dos Patos) apresenta o valor de 1,63, e à medida em que se dirige para jusante os valores vão diminuindo gradativamente, até que na última estação (Novo Porto Taquara) o valor chega a 0,96 . Esta diferença de valores para os extremos setores de montante e jusante é devido ao aumento da área de drenagem e da maior contribuição das vazões dos tributários situados para jusante, fazendo com que a oscilação dos valores tenha um discreto amortecimento e a amplitude entre os picos de descida e subida se torne menor.

Relação descarga líquida $(\mathrm{Q}) \mathrm{x}$ concentração de sólidos suspensos (Cs) O valor de Cs do rio Ivaí na estação estudada apresenta uma correlação relativamente baixa $\left(\mathrm{R}^{2}=0,56\right)$ com Q (Fig. 4). A grande dispersão dos valores se faz notar tanto em águas baixas como nas cheias, sendo, contudo, mais extremas entre as descargas de 500 a $1500 \mathrm{~m}^{3} / \mathrm{s}$, onde foi possível fazer um balanço e verificar que estes valores estão relacionados aos anos de El Niño.

A correlação melhora sensivelmente $\left(\mathrm{R}^{2}=0,82\right)$, no entanto, quando se relaciona a descarga diária de sedimento (Csd) com a vazão diária (Qd) (Fig. 5). Observa-se que o efeito de histerese se dá mais efetivamente nas maiores descargas. Entende-se por histerese o efeito nos quais os mesmos valores de vazão correspondem valores diferentes de concentração de sedimento suspenso. A histerese relaciona a variação temporal na concentração de sedimentos em suspensão para diferentes tipos de vazão (Morehead et al. 2003). A histerese pode ocorrer tanto no período de cheia do canal como no período de vazante. A histerese horária ocorre quando a onda de maior concentração de sedimento suspenso antecede o pico de vazão, no caso inverso tem-se a histerese anti-horária (Stevaux 1994).

$\mathrm{O}$ efeito de histerese pode ser detalhado quando se trabalha com as vazões e a concentração da carga suspensa num evento de cheia (Fig. 6). Para este estudo foi escolhida a cheia do ano de 1977, por ser o período com maior disponibilidade de dados sequenciais. A relação da concentração de sedimentos com os níveis ascendentes e descendentes da vazão resultou e um gráfico de histerese horária, ou seja, o fluxo de maior concentração de sedimentos antecede o pico de cheia. O efeito de histerese horária da bacia do rio Ivaí está provavelmente relacionado à morfologia alongada da bacia. Stevaux (1994) e Drago (1990) observaram histerese anti-horária para cheias do rio Paraná para o qual atribuíram a morfologia mais circular daquela bacia.

Relação temporal da descarga líquida anual (Qa) A descarga líquida anual do rio Ivaí não apresentou alterações significativas durante o período estudado. A curva de tendência da descarga anual é praticamente paralela e equivalente ao valor médio, o que significa ausência de alterações desse parâmetro ao longo da série histórica (Fig. 7).

Quando se analisa o mesmo período, mas sem os eventos de El Niño (Fig. 8), nota-se discreto aumento

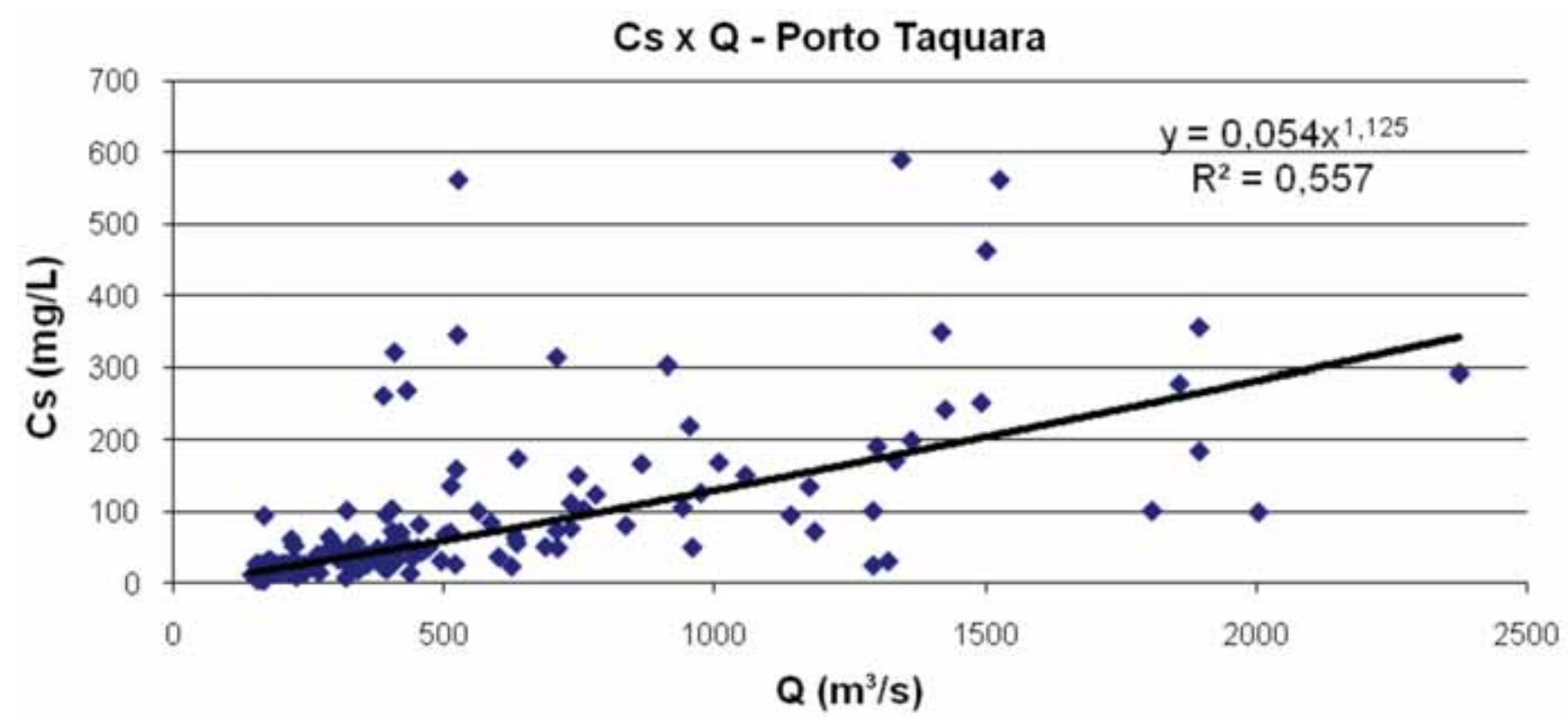

Figura 4 - Correlação entre Cs e Q. 


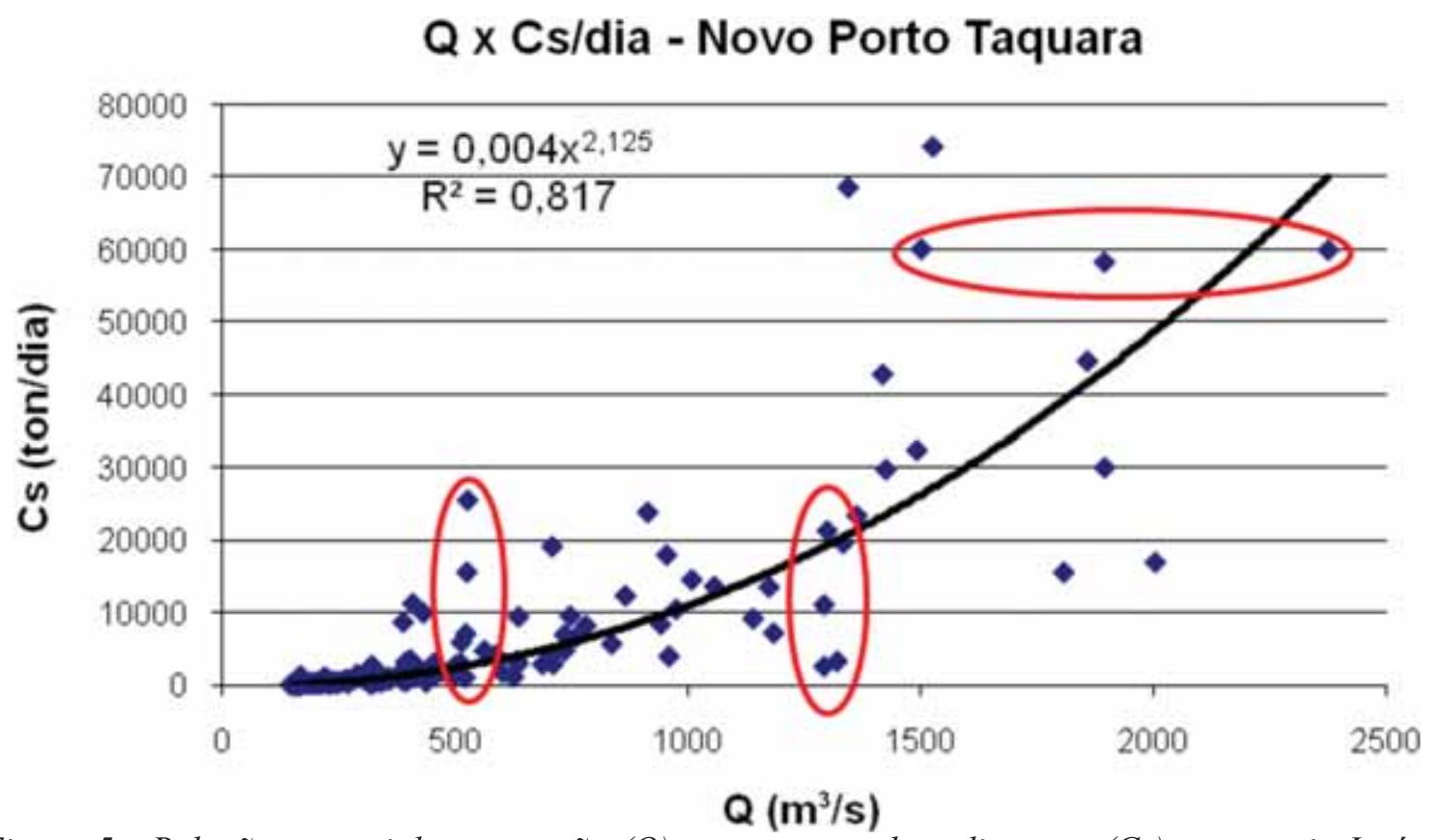

Figura 5 - Relação potencial entre vazão (Q) e transporte de sedimentos (Cs) para o rio Ivaí na estação Novo Porto Taquara. Notar que nos valores maiores de $Q$ ocorre maior variação de Cs, diferentemente dos valores mais inferiores de Q. As elipses indicam prováveis efeitos de histerese.

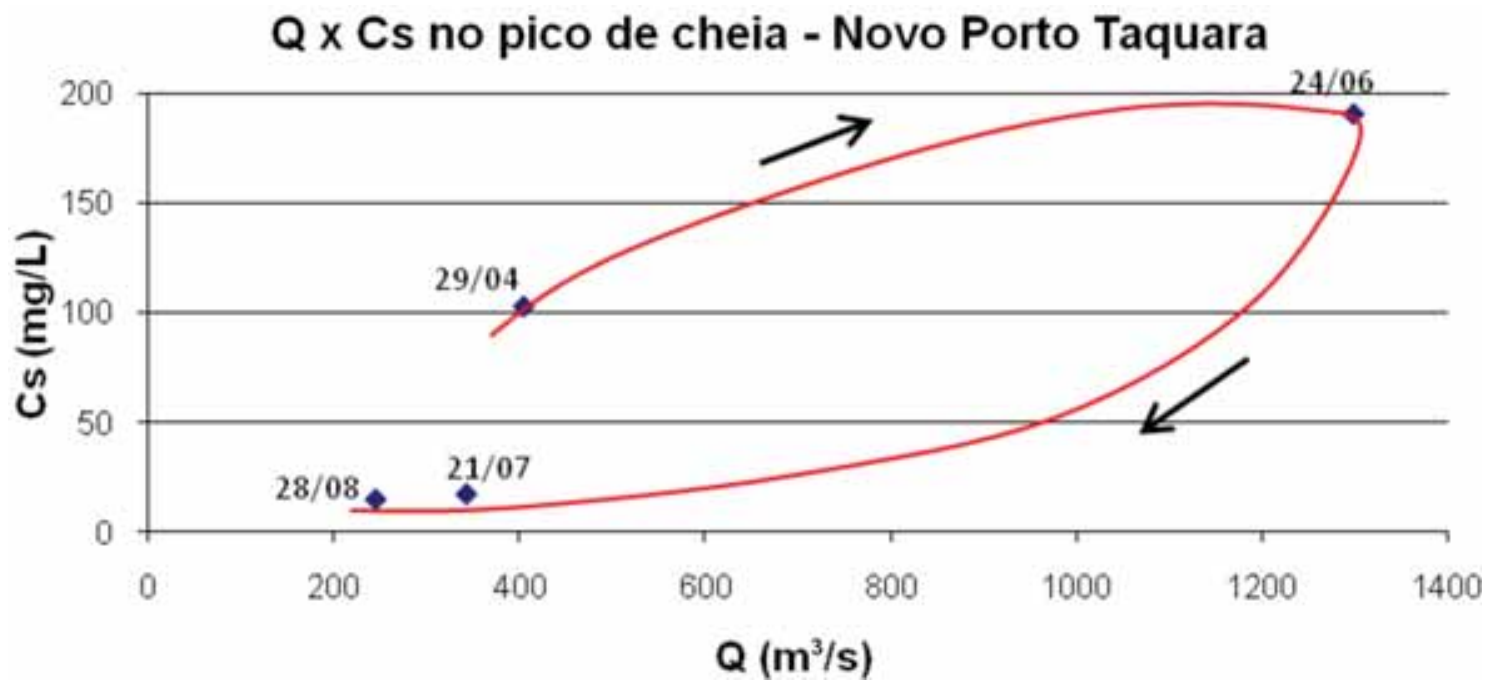

Figura 6 - Relação entre Qa e Cs. Notar o discreto efeito de histerese horária para a cheia do ano de 1977.

nos valores da descarga líquida anual, onde, através da linha de tendência, foi calculado um aumento de 2,75 $\mathrm{km}^{3}$ no decorrer desse período. Andrade (2003) e Baldo (2006) estudando a precipitação na bacia, durante o mesmo período, concluíram que os períodos mais chuvosos concentram, geralmente, os meses de dezembro/ janeiro e fevereiro, sendo esta uma característica estabelecida para toda a área. Os autores verificaram que os anos mais chuvosos foram 1982, 1983, 1992 e 1998 e os menos chuvosos foram 1978, 1985 e 1988. Ao analisar estes anos de máxima e mínima demanda pluviométrica percebe-se que os anos de mínima estão mais distantes no período histórico aqui estudado, enquanto que, para os anos de máxima, existe certa frequência e ascendência temporal. Os resultados obtidos mostram que existe uma relação entre a frequência temporal ascendente na demanda pluviométrica e o aumento da vazão do rio Ivaí para os tempos mais recentes da série histórica.

Variação temporal da descarga anual de sedimento $(Q s)$ Uma pequena redução na produção de sedimento suspenso pode ser observada quando se considera o período estudado (Fig. 9). Para o ano de 1977, obteve-se uma descarga anual de sedimentos de 2,65 Mton que se reduziu para 2,00 Mton para o último ano da série, ou seja, um decréscimo gradual na carga de sedimentos de 


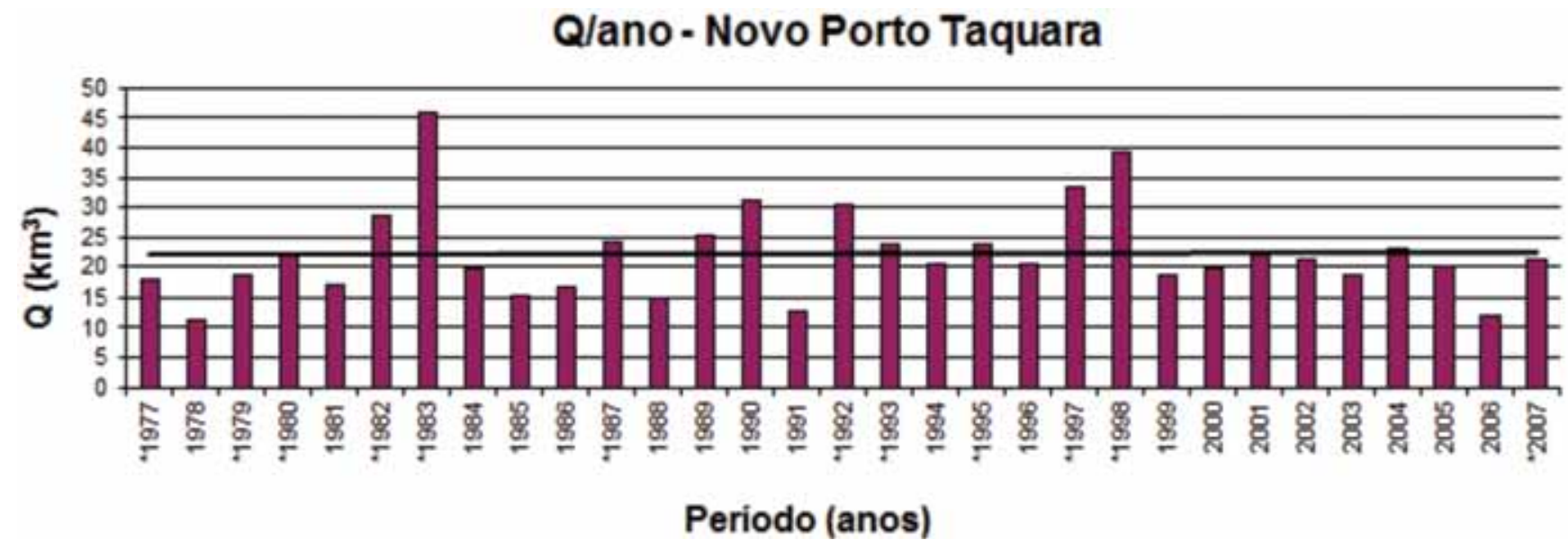

Figura 7 - Descarga líquida anual do rio Ivaí para o período 1977-2007 (* eventos de El Niño).

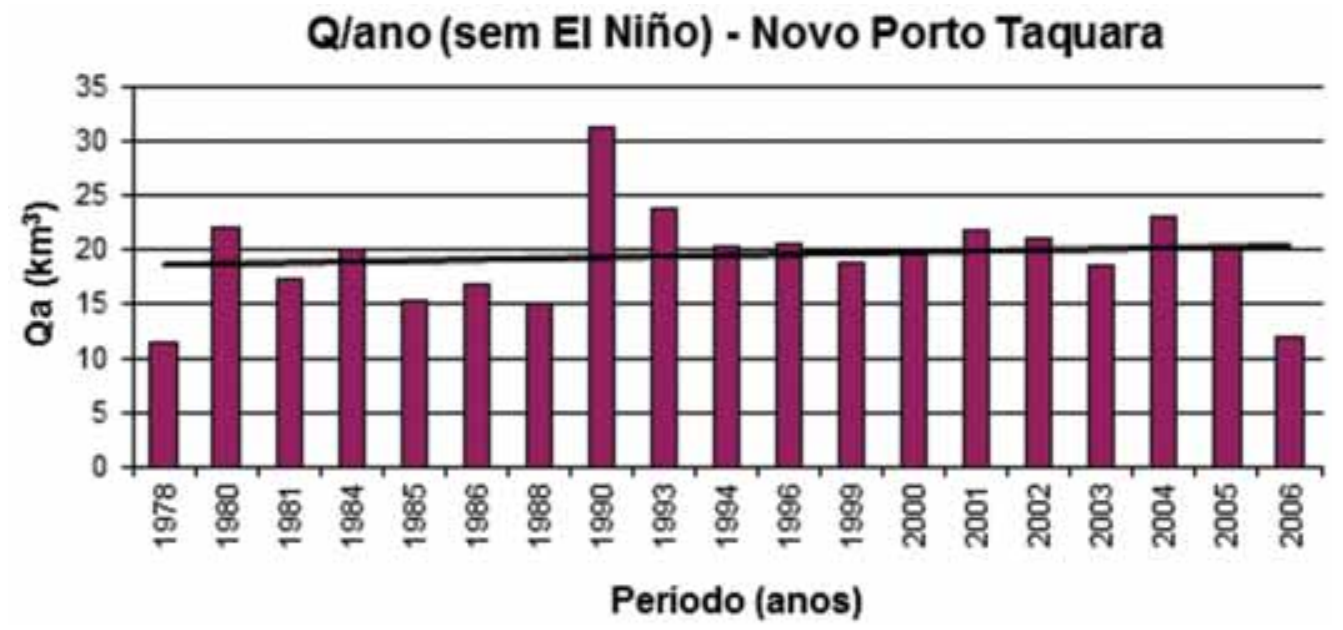

Figura 8 - Descarga líquida anual para o rio Ivaí no período 1978-2006 sem os anos de El Niño.

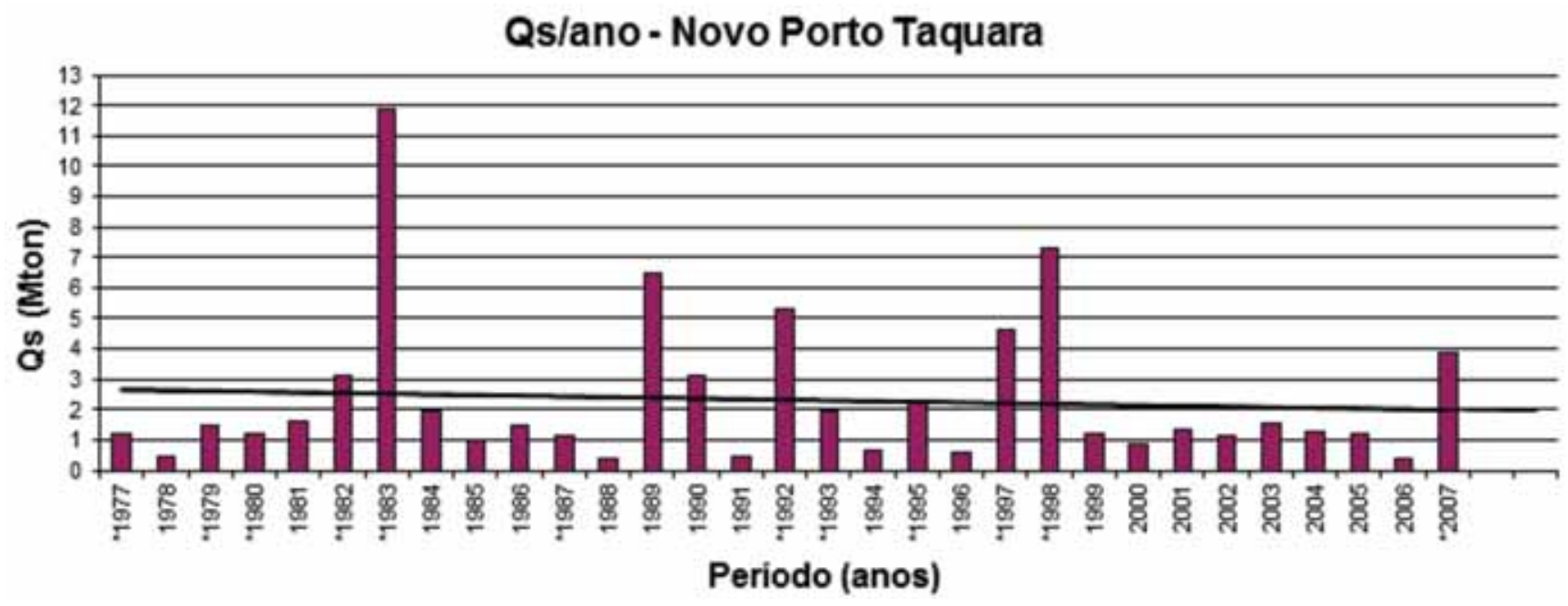

Figura 9 - Cs em milhões de toneladas por ano (* eventos de El Niño).

0,65 Mton (Fig. 9). No entanto, quando a série histórica é analisada sem os eventos de El Niño ocorre que a redução é praticamente inexpressiva caindo para 0,2 Mton, e isto também pode ser observado nos extremos do tempo analisado, quando em 1978 a descarga de sedimentos era de 1,5 milhões de toneladas, e no final do período (2006), a descarga foi de 1,3 milhões de toneladas (Fig. 10). 


\section{Qs/ano (sem El Niño) - Novo Porto Taquara}

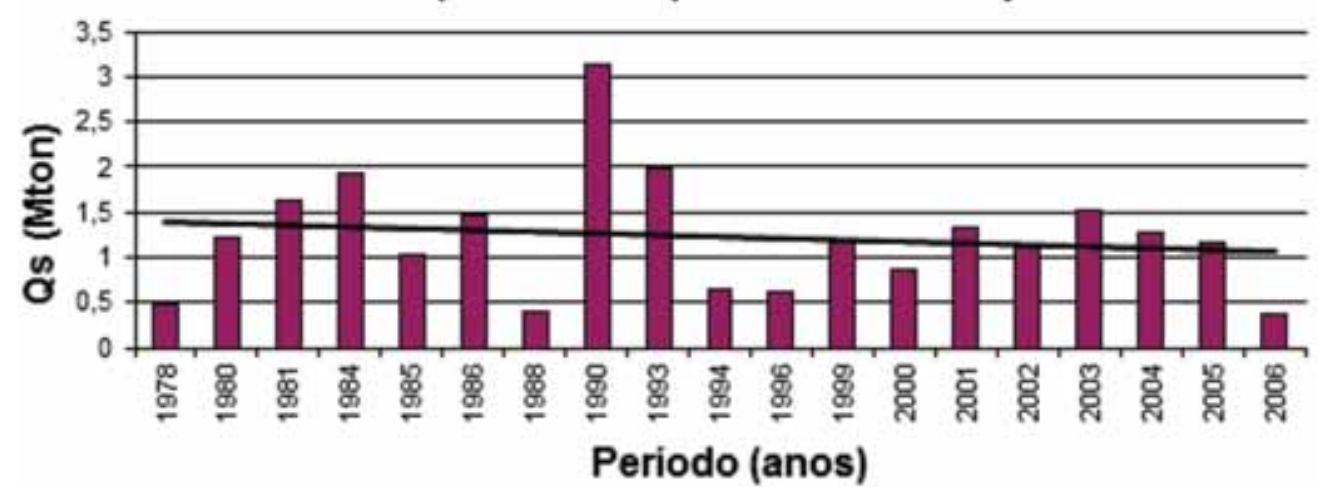

Figura 10 - Cs anual em milhões de toneladas - sem os eventos de El Niño.

Variação temporal da relação entre descarga anual líquida (Qa) e descarga anual de sedimento suspenso (Cs) O homem é um participante ativo no que diz respeito ao ambiente provedor de suas necessidades econômicas, o ambiente natural é, em muitas vezes, muito modificado, podendo sofrer prejuízos de variadas proporções. Uma forma de avaliar o efeito das atividades de origem humana e mudanças do regime climático em tendências temporais do transporte de sedimentos é analisar o gráfico de valores acumulados entre vazão e transporte, conforme sugerido por Restrepo (2005) para o rio Magdalena na Colômbia. Para o presente estudo introduziu-se o coeficiente de produção de sedimento $(\alpha)$ que é dado pela relação $\Delta \mathrm{Cs} / \Delta \mathrm{Qa}$.

Este tipo de análise mostra a tendência do fluxo de sedimentos em relação à vazão. Se as duas variáveis, vazão e transporte de sedimento mostram tendências similares, a pendente do gráfico não se modificará no tempo. Caso contrário, se a taxa de transporte se incrementa ou diminui em relação à da descarga de água, o gráfico mostrará a mudança na pendente original.

Os valores anuais acumulados de vazão e descarga sólida suspensa foram analisados através do gráfico representado pela figura 10 , sendo, no primeiro caso, mesmo se considerando os anos de El Niño, o incremento anual é bastante semelhante entre os anos do período estudado, ou seja, praticamente não houve aumento nos valores de vazão anual. No entanto, em relação à descarga sólida suspensa existe uma tendência de mudanças mais abruptas na série de pontos. Estes intervalos de descontinuidade mais acentuados demonstram que nestes períodos houve uma alteração consideravelmente alta para o volume de sedimento suspenso no canal.

Os anos em que o gráfico apresenta intercorrências em relação ao volume de sedimento suspenso foram ocasionados devido aos eventos do El Niño. Este tipo de intercorrência climática apresentou grande influência sobre a bacia do rio Ivaí durante o período estudado, pois ficou entendido que é durante estes períodos que a bacia sofre maior perda de sedimentos, ocasionando, consequentemente, um grande aumento temporário do volume de sedimento suspenso transportado.
O gráfico de Q e Cs anual acumulados também demonstra uma queda na produção de sedimentos ao longo do tempo estudado, como já foi demonstrado anteriormente pela análise dos gráficos anteriores (Figs. 9 e 10). Ao analisar o gráfico nota-se que a pendente da série histórica se torna menos íngreme conforme se aproxima do tempo atual, o que por si só sugere redução do sedimento suspenso. Todavia, foram calculados os valores de $(\alpha)$ como sendo o coeficiente angular da reta definida pela (Cs x Q) acumulada. Esta análise permitiu concluir que, de fato, o processo de produção e transporte de sedimentos está reduzindo, pois para o começo do período estudado (1977/1981) o sedimento transportado no canal apresentou valor de $\alpha=0,069$ tendo queda discreta, mas progressiva no decorrer do tempo, apresentando, no final da série histórica, o valor de $\alpha=0,044$ entre os anos de (1998/2006), (Fig. 11).

CONCLUSÃO A relação entre a concentração de sedimento suspenso e a vazão líquida não apresenta uma correlação muito boa, principalmente nas descargas maiores. O efeito de histerese, apesar de difícil caracterização, pode ser constatado e evidencia que as maiores descargas de sólido suspenso ocorrem no período de ascensão do pico de cheia. A dificuldade de caracterização da histerese deve-se à ausência de dados contínuos durante os eventos de cheia.

A análise geral da série histórica evidencia que está havendo diferença no comportamento entre a descarga de sedimento suspenso e descarga líquida no canal do rio Ivaí. As figuras $(9,10$ e 11) indicam que, embora discreta, ocorre uma diminuição no transporte de sedimento pelo canal, logo se conclui que as vertentes da bacia tiveram menos perdas de solos durante o período estudado. No entanto, este mesmo comportamento não acontece quando se analisa os gráficos de vazão (Figs. 7 e 8), onde a descarga líquida praticamente não se alterou durante o período estudado.

A redução na carga sedimentar mantém-se mesmo quando se retiram os anos de El Niño da série histórica (Figs. 9 e 10). Paiva (2008) menciona modificações no uso e ocupação da bacia como a implantação de mecanismos de controle de conservação do solo através da implantação de terraceamentos na transição das culturas 
Q $\times$ Qs anual acumulada - Novo Porto Taquara

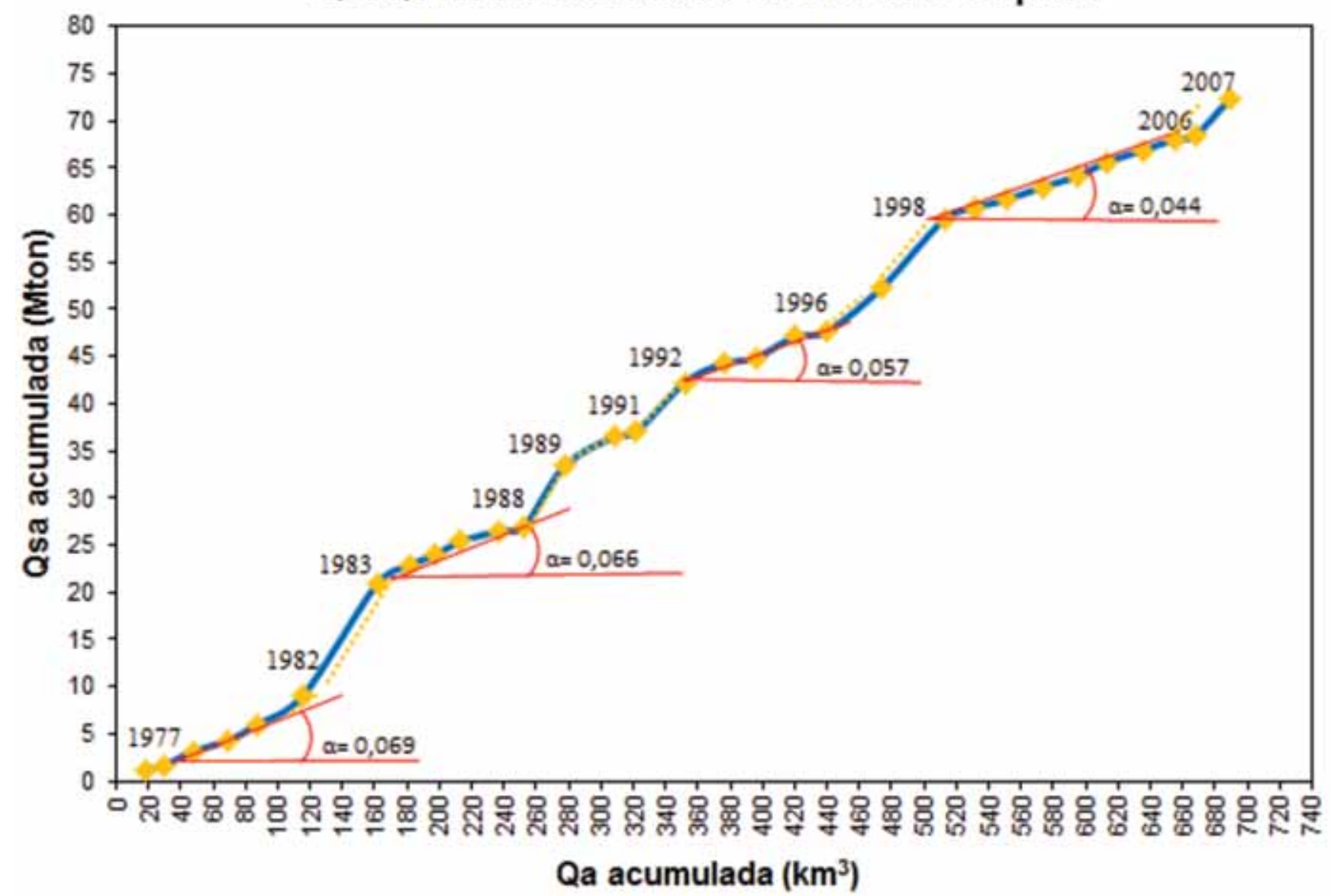

Figura 11 - Gráfico de valores acumulados para vazão e transporte de sedimentos. A tangente de a representa a razão Cs acumulada/Qa acumulada.

permanentes para a cultura temporária. Segundo o autor, o manejo de cuidados com o solo agrícola através das construções de curvas de nível para conter, ou diminuir, as perdas de solo por erosão foi um projeto governamental que teve início na década de 70, e isto teria contribuído para a diminuição de sedimentos levados das encostas até o canal do rio. O declínio no transporte de sedimentos é gradual em toda a série histórica, entretanto, se torna mais acentuado no período dos anos 90 em diante. Este fato pode ser devido a outro tipo de manejo agrícola, o de plantação direta, ou seja, a plantação das sementes agrícolas é feita sem que haja o revolvimento da terra. Acredita-se que a soma dos cuidados com o manejo do solo no cultivo agrícola contribuiu substancialmente na redução da carga suspensa transportada pelo rio Ivaí. Estima-se que nos trinta anos da série histórica estudada houve uma redução total de $0,65 \mathrm{Mton} /$ ano e quando se excluem os anos de El Niño, de 2,00 Mton/ano.
Quando se observa o gráfico de vazão líquida (Qa) e sólida suspensa (Csa) anual acumulada (Fig. 11), percebe-se que não há alteração significativa do incremento de vazão, o que não acontece com a carga suspensa que decresceu discretamente, mas gradualmente. $\mathrm{O}$ valor da razão Csa/Qa (tangente da reta dos pontos da figura 11) apresenta um ligeiro declínio, onde os valores de $\alpha$ são maiores para o começo da série histórica. Para o ano de 1977, o volume de sedimento no canal era de $\alpha=0,069$ e diminui gradualmente durante todo o período, estando em 2006 com o valor de $\alpha=0,044$, indicando a redução na carga de sedimento transportado.

Conclui-se, portanto, que a bacia do rio Ivaí, em que pese sua ocupação, não apresenta mudanças significativas na produção de sedimento nem na vazão líquida ao longo dos últimos 30 anos e que as alterações no uso da bacia podem ter contribuído para uma discreta redução na produção de sedimento. 


\section{Referências}

Andrade A.R. 2003. Variabilidade da precipitação pluviométrica da bacia hidrográfica do rio Ivaí - PR. Dissertação de Mestrado, Departamento de Geografia, Universidade Estadual de Maringá, Maringá, 99 p.

Baldo M.C. 2006. Variabilidade pluviométrica e a dinâmica climática na bacia hidrográfica do rio Ivaí - PR. Tese de Doutorado, Universidade Estadual Paulista, Presidente Prudente, $172 \mathrm{p}$.

Carvalho N.O. 1994. Hidrossedimentologia Prática. Rio de Janeiro, CPRM, 384 p.

Destefani E.V. 2005. Regime Hidrológico do Rio Ivaí - PR. Dissertação de Mestrado, Centro de Ciências Humanas, Letras e Artes, Universidade de Maringá, Maringá, 95 p.

Drago E.C. 1990. Hydrological and geomorphological characteristics of the hidrosystem of the Middle Paraná river. Acta Limnológica Brasileira, 3:907-930.

ITAIPU/BINACIONAL. 1990. Estudo Sedimentométrico no Sistema de ITAIPU. Foz do Iguaçu, GEA, Relatório 06/87-12/88 - v. 1

Maack R. 1981. Geografia física do estado do Paraná. Curitiba, BADEP, 450 p.

Moro A.D. 1991. Substituição de culturas, modernização agrícola e organização do espaço rural, no norte do Paraná. Tese de Doutorado, Departamento de Geografia, Universidade Estadual Paulista, Rio Claro, $353 \mathrm{p}$.

Morehead M.D., Syvitski J.P.M., Hutton E.W., Peckham S.D. 2003. Modeling the temporal variability in the flux of sediment from ungauged river basins. Global and Planetary Change, 39(1-2):95-110.

Paiva D.G. 2008. Análise do índice de relação entre o fluxo de base e desflorestamento por meio de imagens orbitais e análise hidrológica: baixo curso do rio Ivaí. Dissertação de Mestrado, Departamento de Geografia, Universidade Estadual de Maringá, Maringá, 74 p.

Parker G. 1976. On the cause and characteristic scales of meandering and braiding in rivers. Journal of Fluid Mechanics, 76:457-480.

Pitlick J. 1993. Response and recovery of a subalpine stream following a catastrophic flood. Geological Society of America Bulletin, 105(5):657-670 [doi: 10.1130/0016-7606(1993) 105<0657:RAROAS $>2.3$. $\mathrm{CO} ; 2]$.

Restrepo J. 2005. Los sedimentos Del rio Magdalena: Reflejo de la crisis ambiental. Colômbia, Universidad EAFIT, $267 \mathrm{p}$.

Santos M.L., Stevaux J.C., Gasparetto N.V.L., Souza Filho E.E. 2008. Geologia e Geomorfologia da Planície Aluvial do rio Ivaí - PR. Revista Brasileira de Geomorfologia, 9:23-34.

Stevaux J.C. 1994. The upper Paraná river (Brasil): Geomorphology, Sedimentology and Paleoclimatology. Quaternary International, 21:143-161 [doi: 10.1016/1040-6182(94)90028-0].

SUDERHSA - Superintendência de Desenvolvimento de Recursos Hídricos e Saneamento Ambiental. 1977-2008. Dados referentes a toda história de coleta de todas as estações fluviométricas da Bacia do Rio Ivaí. Dados fornecidos por email.

Wilson-Jr G., Rodrigues H.T., Soares J.S. 1980. Estudos Hidráulico e Sedimentológicos Realizados na Parte Inferior do Rio Ivai, Brasil. Belo Horizonte, ARH CDTN/NUCLEBRÁS, 185 p.

Manuscrito ID 17888

Submetido em 30 de junho de 2010 Aceito em 21 de dezembro de 2011 